\title{
Insulin-mediated cortical activity in the slow frequency range is diminished in obese mice and promotes physical inactivity
}

\author{
A. M. Hennige - T. Sartorius • S. Z. Lutz • \\ O. Tschritter • H. Preissl • S. Hopp • A. Fritsche • \\ H.-G. Rammensee $•$ P. Ruth $\cdot$ H.-U. Häring
}

Received: 7 April 2009 /Accepted: 24 July 2009/Published online: 15 September 2009

(C) Springer-Verlag 2009

\begin{abstract}
Aims/hypothesis There is evidence from mouse models and humans that alterations in insulin action in the brain are accompanied by an obese phenotype; however, the impact of insulin with regard to behavioural aspects such as locomotion is unknown.

Methods To address insulin action in the brain with regard to cortical activity in distinct frequency bands and the behavioural consequences, the insulin signalling pathway was followed from the receptor to electrical activity and locomotion. Western blot analysis, electrocorticograms with
\end{abstract}

A. M. Hennige and T. Sartorius contributed equally to this study.

A. M. Hennige $\cdot$ T. Sartorius $\cdot$ S. Z. Lutz $\cdot$ O. Tschritter $\cdot$

S. Hopp $\cdot$ A. Fritsche $\cdot$ H.-U. Häring $(\bowtie)$

Department of Internal Medicine 4, University of Tuebingen,

72076 Tuebingen, Germany

e-mail: Hans-Ulrich.Haering@med.uni-tuebingen.de

T. Sartorius $\cdot$ P. Ruth

Institute of Pharmacy,

Department of Pharmacology and Toxicology,

University of Tuebingen,

Tuebingen, Germany

H. Preissl

Institute of Medical Psychology and Behavioural Neurobiology,

University of Tuebingen,

Tuebingen, Germany

H. Preissl

Department of Obstetrics and Gynecology, College of Medicine, University of Arkansas for Medical Sciences,

Little Rock, AR, USA

H.-G. Rammensee

Department of Immunology, Institute for Cell Biology,

University of Tuebingen,

Tuebingen, Germany intracerebroventricular (i.c.v.) application of insulin, and measurements of locomotor activity were performed in lean and obese, as well as Toll-like receptor (TLR) 2/4-deficient, mice.

Results We show that insulin application i.c.v. into lean mice was accompanied by a profound increase in cortical activity in the slow frequency range, while diet-induced obese mice displayed insulin resistance. In parallel, insulin administered i.c.v. increased locomotor activity in lean mice, whereas a phosphatidylinositol-3 (PI3) kinase inhibitor or obesity abolished insulin-mediated locomotion. A potential candidate that links insulin signalling to locomotion is the Kv1.3 channel that is activated by PI3-kinase. Pharmacological inhibition of Kv1.3 channels that bypassed insulin receptor activation promoted activity. Moreover, mice deficient in TLR2/4-dependent signalling displayed an increase in cortical activity in the slow frequency range that was correlated with improved spontaneous and insulin-mediated locomotor activity.

Conclusions/interpretation Our data provide functional evidence for a direct effect of insulin on brain activation patterns in the slow frequency bands and locomotor activity in lean mice, while in obese mice, insulin-mediated locomotion is blunted and further aggravates physical inactivity.

Keywords Brain - Electrocorticogram - Insulin resistance . Locomotor activity Obesity Toll-like receptor
Abbreviations
ECoG Electrocorticogram
FFT Fast Fourier transformation
i.c.v. Intracerebroventricular
IR Insulin receptor
IRS Insulin receptor substrate 
MEG Magnetoencephalography

PI3 Phosphatidylinositol-3

TLR Toll-like receptor

\section{Introduction}

Insulin is required for a variety of regulatory functions in multiple tissues such as induction of glucose uptake in skeletal muscle, suppression of hepatic glucose production and inhibition of lipolysis in adipose tissue. In addition to the classic insulin-sensitive tissues, the brain has emerged as a major target of insulin action in rodents as well as in humans [1-5]. There is increasing evidence that adequate insulin receptor signalling is required for neuronal survival [6], regulation of food intake [7], determination of lifespan [8] and adequate suppression of hepatic glucose production [9]; however, the insulin-specific activation patterns in cortical activity, their functional consequences and molecular mechanisms are much less clear.

Insulin receptors are expressed all over the brain. The highest densities are in the hypothalamus, hippocampus, olfactory bulb and cerebrocortical tissues, where they display distinct functions [10] and promote tyrosine phosphorylation of proteins that engage in various downstream signalling pathways, including the insulin receptor substrate proteins, and the phosphatidylinositol-3 (PI3) kinase/AKT pathway [11].

We recently demonstrated, using magnetoencephalography (MEG) measurements, that in humans insulin modifies cortical activity in distinct frequency bands, dependent on age, obesity, genetic variations and levels of NEFA. In particular, insulin was able to enhance cortical activity in the beta frequency spectrum in lean and young humans [12], while obese and older individuals displayed insulin resistance [1]. In parallel, an increase in insulin levels led to an improvement in the theta frequency band in normalweight individuals, while obesity, elevated levels of NEFA and genetic variants associated with obesity failed to increase cortical activity in the theta frequency band $[1,13]$. As all of these data were obtained with hyperinsulinaemic-euglycaemic clamp conditions, with permanent insulin application in the periphery combined with a single MEG measurement after $60 \mathrm{~min}$ of insulin infusion, it was not possible to monitor the kinetics closely nor the behavioural aspects in this setting.

To determine the kinetics of insulin action in the brain with regard to brain activity in distinct frequency bands, and to better understand the functional consequences and molecular pathways that are relevant in the pathophysiological state, we established electrocorticogram (ECoG) measurements $[14,15]$ in mice in combination with a cannula placed in the lateral ventricle to deliver substances directly. Thereby, insulin action could be tightly linked to activation patterns in electrical activity in the mouse brain and finally to behaviour.

By using this approach, the consequences of modulating insulin signalling in brain tissues by obesity and effects of pharmacological inhibition of ion channels were detected and correlated to brain activity and locomotion.

\section{Methods}

Animals We obtained C57BL/6NCrl male mice from Charles River Laboratories (Sulzfeld, Germany). They were maintained on a $12 \mathrm{~h}$ light-dark cycle and kept on either chow or were weaned on a high-fat diet for 8 weeks [16]. Mice with a knockout for Tlr 2 on a $\mathrm{C} 3 \mathrm{H} / \mathrm{HeJ}$ background $(\mathrm{C} 3 \mathrm{H} / \mathrm{HeJ} / \mathrm{TLR} 2-\mathrm{KO})$ were obtained from H. Schild (Institute for Immunology, Johannes Gutenberg University, Mainz, Germany) who originally received them from $\mathrm{H}$. Wagner (Institute of Medical Microbiology, Immunology and Hygiene, Technische Universität München, Munich, Germany) [17]. All procedures were conducted according to the guidelines of laboratory animal care and were approved by the local governmental commission for animal research.

In vivo stimulation and western blot analysis For in vivo stimulation, a bolus of human insulin (Novo Nordisk, Bagsvard, Denmark; $1 \mathrm{U} /$ mouse for $5 \mathrm{~min}$ ) was injected into the inferior vena cava of overnight-fasted mice. Control mice received a comparable amount of $\mathrm{NaCl}$. Total brain tissues were removed and homogenised at $4{ }^{\circ} \mathrm{C}$. Homogenates were allowed to solubilise for $15 \mathrm{~min}$ on ice and clarified by centrifugation at $12 \times 000 \mathrm{~g}$ for $20 \mathrm{~min}$. To detect tyrosine phosphorylation of the insulin receptor or insulin receptor substrate 2 (IRS2) proteins, lysates containing equal amounts of protein were immunoprecipitated with antibodies directed against insulin receptor (IR) [18] or IRS2 (Millipore, Schwalbach, Germany). Visualisation of immunocomplexes after gel electrophoresis and western blotting was performed using PY 20 antibodies (Santa Cruz, La Jolla, CA, USA) and the non-radioactive enhanced chemiluminescence system ECL. Equal protein amounts were verified using $\beta$-tubulin antibodies (Millipore).

Chronic i.c.v. cannulation and implantation of electrocorticography telemetry transmitters At least 1 week before experimentation, each mouse had an implantable telemetry electrocorticography transmitter inserted and was instrumented with a guide cannula for microinjection of substances into the lateral ventricles. Briefly, animals were anaesthetised with isoflurane $(5 \%$ [vol./vol.] induc- 
tion, $1.5 \%$ [vol./vol.] maintenance) and placed in a stereotaxic head holder. The body of the telemetry transmitter was implanted subcutaneously and two lead wires were connected to screws placed epidurally $1 \mathrm{~mm}$ anterior to lambda and $1 \mathrm{~mm}$ left to the sutura sagittalis for the recording electrode, and $1 \mathrm{~mm}$ anterior to bregma and $1 \mathrm{~mm}$ right to the sutura coronaria for the reference electrode. A sterile $27 \mathrm{G}$ stainless steel cannula $6 \mathrm{~mm}$ in length was implanted in the left lateral ventricle of the brain with the following coordinates: $0.3 \mathrm{~mm}$ posterior and $1 \mathrm{~mm}$ lateral relative to bregma, and $3.0 \mathrm{~mm}$ down the skull surface. Electrodes, screws and cannula were then fixed in place with dental acrylic cement, and the scalp sutured closely around the resulting wound with non-absorbable 50 suture material (Ethilon polyamide; Ethicon, Norderstedt, Germany). A tubing dummy prevented blockage of the cannula. The correct position of the i.c.v. cannula was verified at the end of the experiments by dye injection into the ventricles before animals were killed.

\section{Intracerebroventricular injection and locomotor activity Mice} deprived of food overnight but with free access to water were injected by connecting the cannula via a polyethylene catheter to a microinjector (CMA/Microdialysis, Solna, Sweden). Compounds injected i.c.v. were dissolved in sterile $\mathrm{NaCl}$ solution and delivered in a volume of $2 \mu \mathrm{l}$ over $1 \mathrm{~min}$.

The mice received an injection of either human insulin (3.75 mU total, Novo Nordisk), vehicle $(0.9 \%$ [wt/vol.] $\mathrm{NaCl})$, wortmannin $(0.01 \mu \mathrm{g}$ total $30 \mathrm{~min}$ prior to insulin; Sigma Aldrich, Taufkirchen, Germany) or margatoxin (5 ng total, Sigma Aldrich) in random order 4 days apart. Telemetry signals (ECoG and locomotor activity) were recorded continuously for $120 \mathrm{~min}$ post injection processed by a Data-Sciences analogue converter (Data Exchange Matrix, DSI, St Paul, MN, USA) and stored digitally using the Dataquest A.R.T. 3.1 software (DSI). Electrocortical activity was sampled at $250 \mathrm{~Hz}$ with a filter cut-off of $40 \mathrm{~Hz}$. Locomotor activity was measured by detecting the changes in signal strength that occurred as the animals moved about their cages. Changes in signal strength of more than a predetermined threshold generated a digital pulse, which was counted by the data-acquisition system. For detection of locomotor activity, the transmitter itself had to move.

Intraperitoneal glucose tolerance test Intraperitoneal glucose tolerance tests were performed in mice after a $16 \mathrm{~h}$ overnight fast. Mice were injected i.p. with $2 \mathrm{~g}$ D-glucose $/ \mathrm{kg}$ body weight, and blood glucose concentrations were determined in tail bleeds using a Glucometer Elite (Bayer, Elkhart, IN, USA) at 0, 15, 30, 60 and $120 \mathrm{~min}$.

Assay of PI3 kinase activity Lean and obese mice were injected i.v. with either $\mathrm{NaCl}$, insulin (1U/mouse for $5 \mathrm{~min}$ ) or wortmannin $(15 \mu \mathrm{g} / \mathrm{kg}$ mouse for $30 \mathrm{~min})$ followed by insulin, and brain lysates were immunopurified with anti-PY20 antibodies (Santa Cruz) and immunocomplexes were adsorbed to protein A-Sepharose for $12 \mathrm{~h}$. Immunoprecipitates were washed three times and pellets were directly incubated with $0.1 \mathrm{mg} / \mathrm{ml} \mathrm{L}-\alpha$-phosphatidylinositol (Sigma) and $50 \mu \mathrm{mol} / 1\left[\gamma^{32} \mathrm{P}\right]$-ATP (Perkin Elmer, Waltham, MA, USA) at room temperature for $10 \mathrm{~min}$. After addition of $150 \mu \mathrm{l}$ of $1 \mathrm{~mol} / \mathrm{l} \mathrm{HCl}$, lipids were extracted twice with $450 \mu \mathrm{l}$ chloroform/methanol (1:1 by volume). Products were separated by thin layer chromatography as described [19]. ${ }^{32} \mathrm{P}-$ labelled phospholipids were detected by autoradiography.

Data analysis and statistics The data analysis for ECoG measurements was performed as previously described [15]. Briefly, fast Fourier transformation (FFT) for delta (0.5$4 \mathrm{~Hz})$, theta $(4-8 \mathrm{~Hz})$, alpha $(8-12 \mathrm{~Hz})$ and beta $(12-30 \mathrm{~Hz})$ frequency bands was used to calculate the power spectral density. Basal results for untreated lean and obese C57BL/ $6 \mathrm{NCrl}$ mice as well as TLR2/4-deficient mice and the corresponding $\mathrm{C} 3 \mathrm{H} / \mathrm{HeJ}$ control group were recorded as absolute ECoG power in $\left(\mu \mathrm{V}^{2} / \mathrm{Hz}\right)$. From our experience, inter-individual variation in baseline cortical activity becomes noticeable after i.c.v. application within the subsequent $120 \mathrm{~min}$ recording period because of stress inducement. To exclude such inter-individual variation in baseline cortical ECoG activity of lean and obese C57BL/ $6 \mathrm{NCrl}$ mice, the data for the $\mathrm{ECoG}$ power density are expressed as percentage change from baseline (vehicle) with $0 \%$ as baseline. Data are presented as mean \pm SEM. The total number of animals tested in each group is indicated by $n$, and the experiments were separately performed. A $p$ value $<0.05$ was considered to indicate statistical significance. Differences between multiple groups were carried out using one-way analysis of variance. When appropriate, we used the non-parametric Wilcoxon/ Kruskal-Wallis rank test. The groups were compared with a post hoc Tukey Kramer HSD comparison test. All analyses were performed using the software package JMP 4.0 (SAS Institute, Cary, NC, USA).

\section{Results}

Insulin-mediated alterations in cortical activity estimated by electrocorticography and correlation to locomotor activity To determine insulin-mediated activation patterns in cortical activity, insulin was administered by intracerebroventricular injection and modulation of brain activity in certain frequency bands was followed from electrocorticogram recordings (Fig. $1 \mathrm{a}-\mathrm{h}$ ). There was an increase in cortical beta and alpha activity (Fig. 1 a-d, black bars) and, to a greater extent in the slow frequency 
Fig. 1 Power spectral density and locomotor activity following i.c.v. insulin application in lean and obese C57BL/6Crl mice. a-h Power spectral density in overnight-fasted lean (black, $n=7$ ), wortmanninpretreated lean (dashed, $n=4$ ), and high-fat-fed (grey, $n=4$ ) mice, indicated for the beta (a, c 12-30 Hz), alpha (b, d

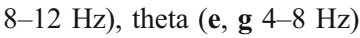
and delta (f, h $0.5-4 \mathrm{~Hz}$ ) frequency bands were calculated by FFT for a $120 \mathrm{~min}$ period following i.c.v. application of insulin (3.75 mU total) and expressed as \% of the saline result. ${ }^{*} p<0.05$ vs the corresponding time interval after insulin application in lean mice. A representative gel used to determine PI3-kinase activity following insulin administration in brain tissues of lean mice is shown in the insert of $\mathbf{a}$. Pre-treatment with wortmannin (Wort) inhibited PI3-kinase activity in lean mice. $\mathbf{i}, \mathbf{j}$ Locomotor activity following i.c.v. application of insulin in overnight-fasted lean (i, black, $n=7$ ), wortmannin-pretreated lean (i, dashed, $n=4$ ), and obese ( $\mathbf{j}$, grey, $n=4)$ mice for the $0-40,40-80$ and $80-120 \mathrm{~min}$ period post injection ${ }^{*} p<0.05$ compared with insulin application for the indicated period). HI, human insulin; PI-3P, phosphatidylinasitol 3-phosphate

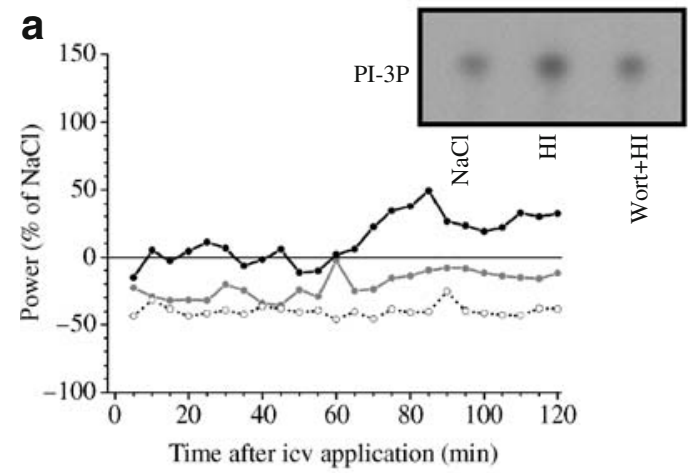

b
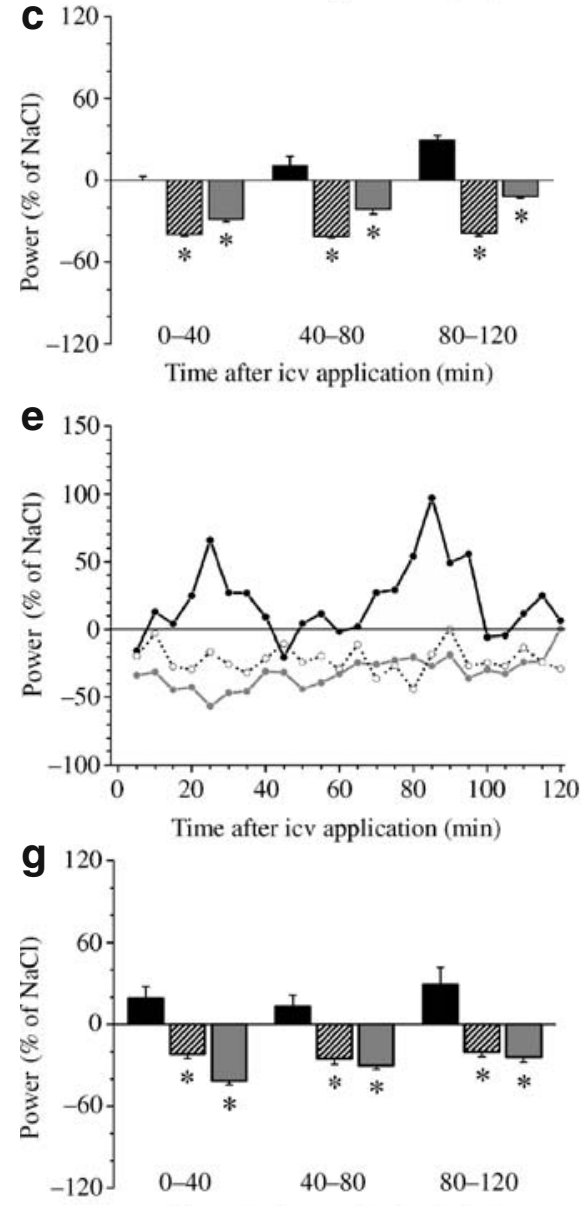

i

Time after icv application (min)

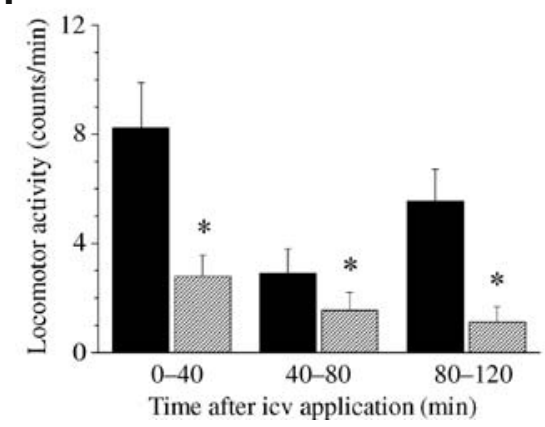

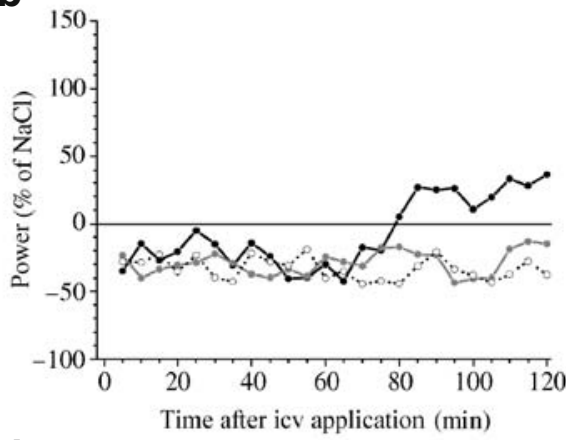

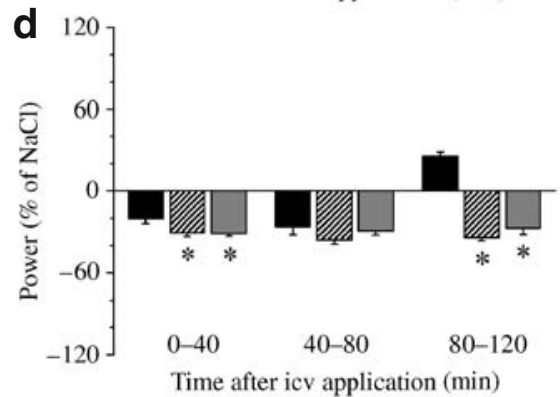

f
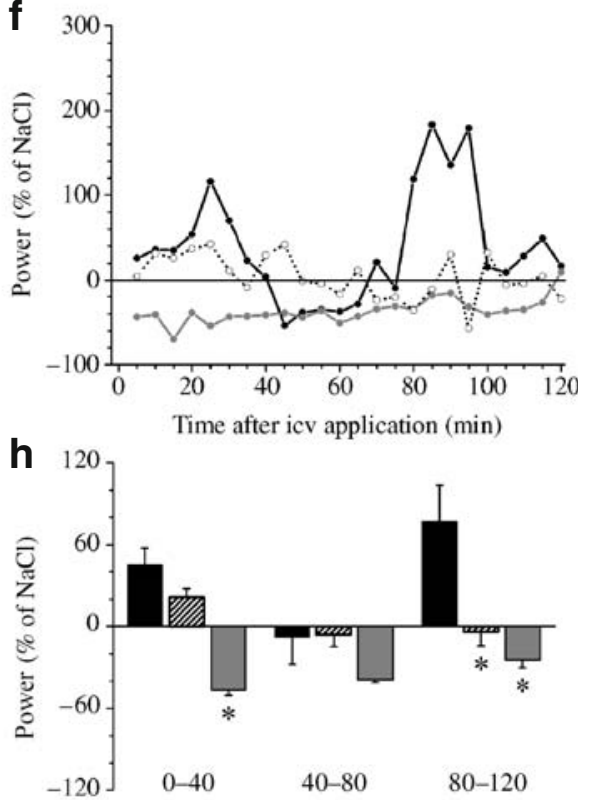

j

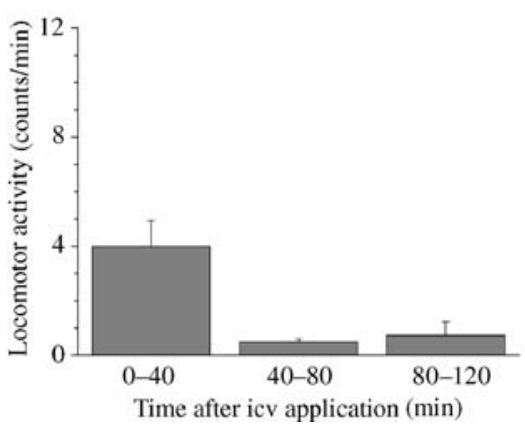


a
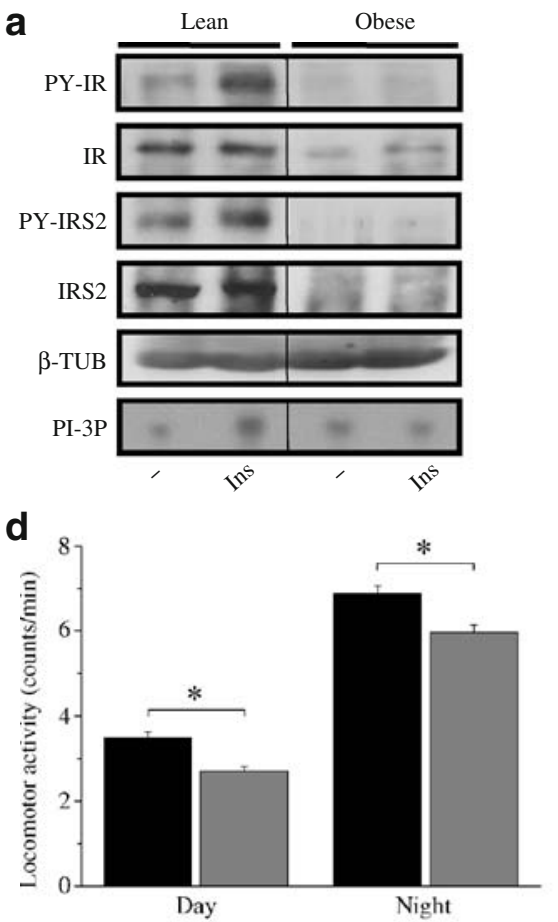

b
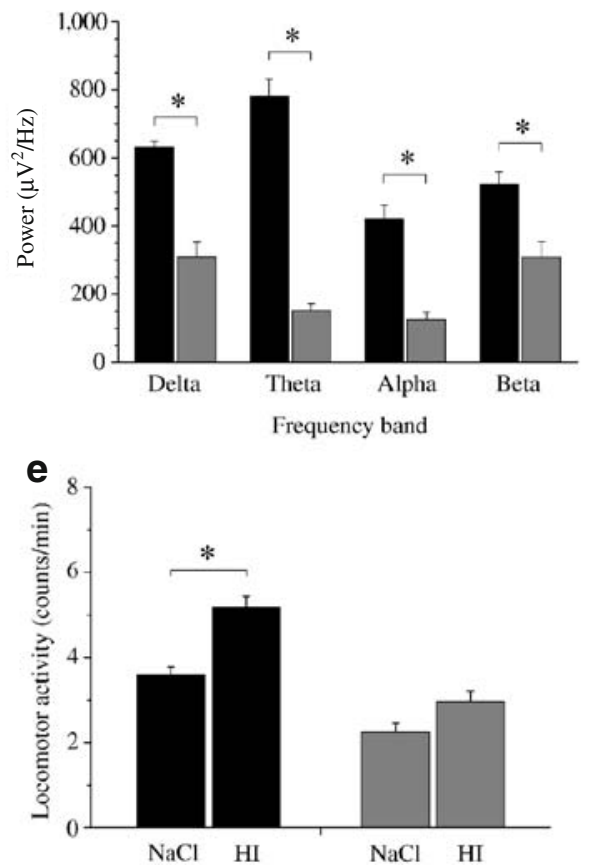

C
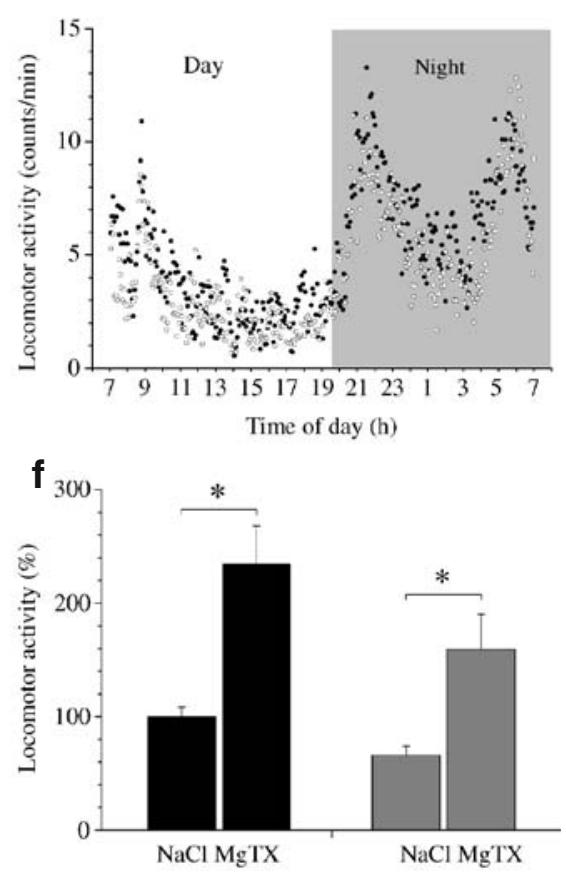

Fig. 2 Tyrosine phosphorylation of insulin receptor and insulin receptor substrate 2 proteins and PI3-kinase activity in total brain lysates after intravenous insulin injection in overnight-fasted lean and obese mice. a Tyrosine phosphorylation of the IR and IRS2 as well as PI3-kinase activity in lean and obese mice. Membranes were reprobed with the respective anti-insulin receptor and anti-IRS2 antibodies. That similar amounts of protein were transferred was ensured by blotting for $\beta$ tubulin ( $\beta$-TUB). For PI3-kinase activity, brain lysates were immunopurified with anti-PY20 antibodies and immunocomplexes were adsorbed with protein A-Sepharose. One representative experiment is shown from three independent experiments. b Basal power spectral density (indicated for the delta $[0.5-4 \mathrm{~Hz}]$, theta [4-8 Hz], alpha [8$12 \mathrm{~Hz}]$ and beta $[12-30 \mathrm{~Hz}]$ frequencies) estimated by ECoG in lean (black) and obese (grey) mice was calculated by FFT for a $120 \mathrm{~min}$ period $(* p<0.05 ; n=3$ per group). $\mathbf{c}$ Locomotor activity of lean (black circles, $n=8$ ) and obese (white circles, $n=8$ ) C57BL/6Crl mice during the day (07:00-19:00 hours) and night (19:00-07:00 hours) cycles. Results from an average of a 4 day period are given. $\mathbf{d}$ Quantification of locomotor activity of lean (black) and obese (grey) C57BL/6Crl mice over an average of a $12 \mathrm{~h}$ day and $12 \mathrm{~h}$ night cycle period $\pm \operatorname{SEM}\left({ }^{*} p<\right.$ $0.05 ; n=8$ per group). e Locomotor activity following i.c.v. application of $\mathrm{NaCl}$ or insulin $(3.75 \mathrm{mU}$ total) in overnight-fasted lean (black) and obese (grey) C57BL/6Crl mice. Quantification of locomotor activity in counts/min \pm SEM for the 120 min measurement, $n=4\left({ }^{*} p<0.05\right)$. f Quantification of locomotor activity after i.c.v. application of $\mathrm{NaCl}$ or margatoxin (MgTX) in lean (black) and obese (grey) mice for the 120 min measurement period, $n=4$. Data are given in counts $/ \min \pm$ SEM $(* p<0.05)$ ranges, theta (Fig. 1e, g, black bars) and delta (Fig. 1f, h, black bars) as previously suggested by our MEG measurements in normal-weight humans. Of note, insulin applied i.c.v. promoted cortical activity in the slow frequency bands with a first peak between minutes 0 and 40 and a second 80 120 min post injection (Fig. $1 \mathrm{e}-\mathrm{h}$, black bars). As insulin signalling in the brain involves activation of PI3-kinase, we determined insulin-mediated brain activity in the presence of wortmannin in lean mice (Fig. 1a, insert). Clearly, induction in all of the frequency bands was abolished using wortmannin prior to insulin administered i.c.v., suggesting that the insulinmediated increase in these frequency bands is PI3-kinase dependent (Fig. $1 \mathrm{a}-\mathrm{h}$, dashed bars).

While it was not possible to correlate activity in the slow frequency band with behavioural readouts in human studies using the hyperinsulinaemic-euglycaemic clamp technique and MEG, it was clearly shown in rodents that active exercise resulted in power increases in the theta frequency band [20]. To translate insulin-mediated modulation in the slow frequency band to behaviour, locomotion in freely moving mice following i.c.v. administration of insulin was monitored by a permanently implanted telemetric sensor. To validate the association of brain activity in the slow frequency bands with locomotor activity, locomotion was analysed in the $0-40,40-80$ and $80-120$ min intervals in the post-injection period. Clearly, insulin-mediated changes in the theta and delta frequency bands following insulin injection were accompanied by an increase in locomotor activity, with its most prominent effect within the first 40 min following insulin injection and between minutes 80 and 120 (Fig. 1i, black bars) when cortical activity in the theta and delta band was enhanced. Consistent with these results, insulin failed to stimulate locomotion after pretreatment with wortmannin (Fig. 1i, dashed bars); this reflects 


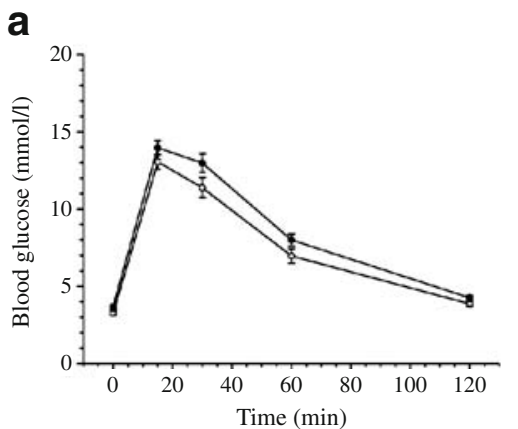

d

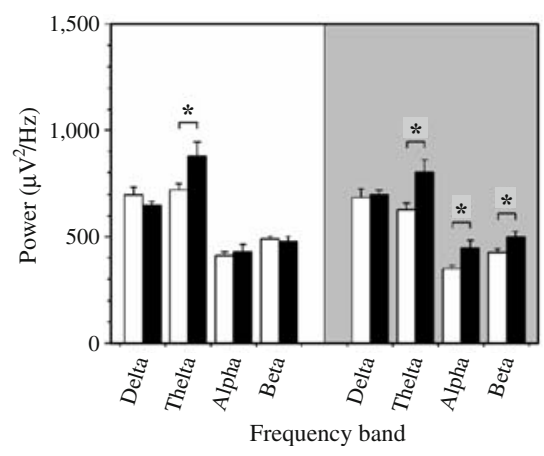

b

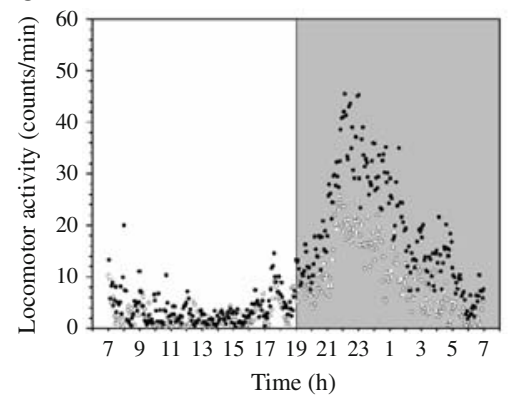

e

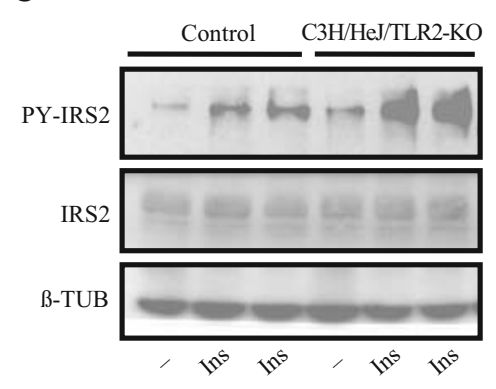

C

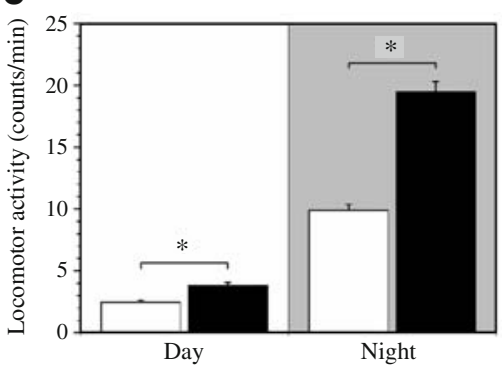

f

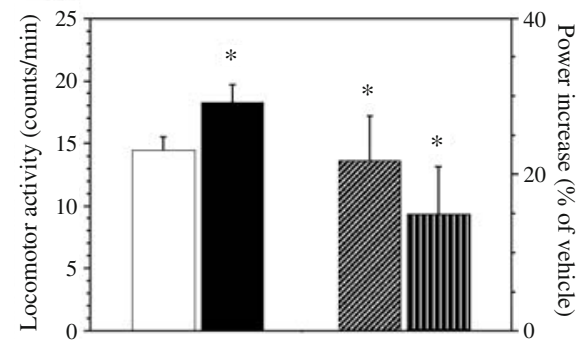

Fig. 3 Glucose tolerance tests, cortical activity and locomotion in TLR2/4-deficient mice. a Glucose tolerance tests were performed in 12 week old fasted control $(n=25)$ and C3H/HeJ/TLR2-KO mice $(n=$ 18) with an i.p. injection of $2 \mathrm{~g} \mathrm{D}$-glucose $/ \mathrm{kg}$ body weight, and blood glucose concentrations were determined in tail bleeds at $0,15,30,60$ and $120 \mathrm{~min}$. b Locomotor activity of control (white circles) and $\mathrm{C} 3 \mathrm{H} /$ HeJ/TLR2-KO (black circles) mice is shown. The results are the average of a 4 day period, $n=4$ per group. c Quantification of locomotor activity of control (white bars) and $\mathrm{C} 3 \mathrm{H} / \mathrm{HeJ} / \mathrm{TLR} 2-\mathrm{KO}$ mice (black bars); the results are the average of $12 \mathrm{~h}$ day and $12 \mathrm{~h}$ night cycle period \pm SEM ( ${ }^{*} p<0.05 ; n=4$ per group). d Basal power spectral density (indicated for the delta $[0.5-4 \mathrm{~Hz}]$, theta $[4-8 \mathrm{~Hz}$, alpha $[8-12 \mathrm{~Hz}]$, and beta $[12-30 \mathrm{~Hz}]$ frequencies) estimated from ECoGs in control (white bars) or $\mathrm{C} 3 \mathrm{H} / \mathrm{HeJ} / \mathrm{TLR} 2-\mathrm{KO}$ mice (black bars) was calculated by FFT for a $120 \mathrm{~min}$ period $\left({ }^{*} p<0.05 ; n=4\right.$ per group). Basal experiments (locomotor activity and ECoG) were jointly

the inability of insulin to increase locomotor activity in an insulin-resistant state.

To resemble an obese and insulin-resistant phenotype, mice were weaned on a high-fat diet for 8 weeks [21]. Measurements of cortical activity in diet-induced obese mice revealed that insulin injected i.c.v. was not able to increase cortical activity in any of the frequency bands (Fig. $1 \mathrm{a}-\mathrm{h}$, grey bars), and this was accompanied by the inability of insulin to increase locomotor activity (Fig. 1j) in obese mice.

Insulin action, cortical activity and locomotion in an animal model of insulin resistance To verify insulin resistance in the brain of mice fed a high-fat diet, western blot analysis and PI3-kinase activity assays were performed. These demonstrated that the activation of the insulin receptor signalling cascade was consistently lower performed in $\mathrm{C} 3 \mathrm{H} / \mathrm{HeJ} / \mathrm{TLR} 2-\mathrm{KO}$ mice and their control group. e Tyrosine phosphorylation of insulin receptor substrate 2 in total brain lysates of mice stimulated with insulin intravenously (Ins). Membranes were reprobed with the respective antibodies to ensure equal protein concentrations. One representative western blot is shown from three independent experiments. $\beta$-TUB, $\beta$-tubulin. f Locomotor activity of overnight-fasted control $(n=4$, white bar) and $\mathrm{C} 3 \mathrm{H} / \mathrm{HeJ} /$ TLR2-KO mice ( $n=4$, black bar) following i.c.v. application of human insulin $(3.75 \mathrm{mU}$ total) for the subsequent $120 \mathrm{~min}$ measurement $\left({ }^{*} p<0.05\right.$ compared with control mice). ECoG power increase ( $\%$ of vehicle) of $\mathrm{C} 3 \mathrm{H} / \mathrm{HeJ} / \mathrm{TLR} 2-\mathrm{KO}$ mice $(n=4)$ was evaluated in the slow frequency bands, delta (cross-hatched bar) and theta (vertically striped bar), directly after i.c.v. application for the $120 \mathrm{~min}$ measurement $\left({ }^{*} p<0.05\right.$ compared with vehicle). Data are given in counts/min \pm SEM for locomotor activity and in power increase ( $\%$ of vehicle) \pm SEM for ECoG activity

in obese mice because of impaired tyrosine phosphorylation and expression of the insulin receptor and insulin receptor substrate 2 proteins as well as impaired PI3-kinase activity in brain tissues (Fig. 2a). Measurements of average basal cortical activity revealed a significant reduction in mice fed a high-fat diet compared with lean animals, with the most prominent discrepancy in the slow theta rhythm (Fig. 2b).

In parallel with the discrepancy in cortical activity, mice displayed significant differences in locomotor activity during the day and night cycle, and mice fed a high-fat diet were less active than lean animals (Fig. 2c, d). While i.c.v. insulin delivery into lean mice led to a significant increase in locomotor activity compared with saline (Fig. 2e, left panels), insulin-mediated locomotion was abolished in obese in the $120 \mathrm{~min}$ post-injection interval (Fig. 2e, right panels, $p>0.05$ ). Therefore, the metabolic state in diet-induced obese mice is tightly correlated with a 
deficit in brain activity in the slow frequency spectrum and physical inactivity that even persists in the face of acutely raising insulin levels in the brain.

Modulation of locomotor activity by a selective inhibitor of the Kv1.3 channel Up to now, the signalling molecules involved in insulin-mediated locomotion have been unknown; however, there is evidence that insulin mediates its function in brain tissues through the phosphorylation of potassium channels and subsequent neurotransmitter expression. In particular, the voltage-dependent Kv1.3 channel is a major candidate as insulin has been shown to inactivate Kv1.3 channels when phosphorylated at multiple sites of the Kv1.3 ion channel protein, and the related pathway involves PI3-kinase [22]. We therefore tested whether Kv1.3 channels are involved in the insulin signalling cascade in brain tissues that potentially induces locomotor activity and used the specific Kv1.3 inhibitor margatoxin to bypass activation of insulin receptors. Application of margatoxin into lean (Fig. 2f, black columns) and obese (Fig. 2f, grey columns) mice profoundly increased locomotor activity, even in obese mice where insulin was unable to promote locomotion. Together, these data suggest that the insulin signalling cascade is disrupted at the levels of the insulin receptor and postreceptor signalling molecules such as IRS2 and PI3kinase in diet-induced obese mice, while the signalling cascade is intact at the level of Kv1.3 channels.

Cortical activity and locomotion in an animal model of enhanced insulin signalling in the brain To identify potential mediators of insulin resistance in the brain that contribute to impaired activity in frequency bands related to physical activity, a mouse model of deficient Toll-like receptor signalling was screened for cortical activity and locomotion.

While Toll-like receptors have been implicated in the pathogenesis of NEFA-induced insulin resistance in the periphery, the role of TLRs with regard to insulin action in the brain is unknown. Consistent with previous results [23], chow-fed TLR2/4-deficient mice displayed no significant differences in fasting blood glucose levels, glucose tolerance tests (Fig. 3a) or body weight (wild type: $22.9 \mathrm{~g} \pm$ $0.9 \mathrm{~g}$; TLR2/4-deficient: $22.2 \mathrm{~g} \pm 0.6 \mathrm{~g}$ ). Looking at locomotor activity, mice deficient of TLR $2 / 4$ signalling displayed enhanced activity during the day and night cycles (Fig. $3 \mathrm{~b}$ and c), and this was clearly reflected by improved brain activity in the theta frequency band (Fig. 3d). In parallel, basal as well as insulin-stimulated tyrosine phosphorylation of IRS2 in the brain was significantly enhanced in TLR2/4-deficient mice (Fig. 3e; $p<0.05, n=3$ ), and was accompanied by significantly increased insulinmediated locomotor activity in TLR2/4-deficient mice (Fig. 3f, left panels). In keeping with this, insulin modulated cortical activity in the slow frequency bands (Fig. 3f, right panels) to a greater extent in TLR2/4deficient mice than in controls. Therefore, TLR2/4 signalling seems to be a determinant of impaired brain activity in the slow frequency bands that finally leads to physical inactivity.

\section{Discussion}

There is evidence from mouse models that alterations in the insulin signalling pathway in the brain are accompanied by an obese phenotype, and this was recently confirmed also in overweight humans $[1,24]$. Here, we show that levels of locomotor activity are dependent on insulin action in the brain as impaired insulin signalling and cortical activity in the slow frequency bands were accompanied by less physical activity. This is supported by a recent study demonstrating that mice with disrupted insulin signalling in the hypothalamus are less active than controls [8].

While we described a profound correlation of impaired insulin-mediated theta activity in the human brain with obesity [1, 13], the current data from our mouse models suggest that the decrease in theta activity is accompanied by impaired locomotor activity. This is in accordance with the limited number of studies investigating cortical brain activation during spontaneous locomotion [25] demonstrating that during mental navigation, neocortical and hippocampal theta activity increased [26], and active exercise resulted in power increases in the theta frequency band [20]. Insulin application into the brain predominantly enhances rhythm in the slow frequency ranges in lean mice, whereas in the presence of a high-fat diet, activity in these frequency bands remained dramatically diminished.

The overall meaning of impaired ECoG power density in obese mice in all of the frequency bands remains unclear from our data. However, former studies suggested that in obese and diabetic individuals, atrophy in the hippocampus occurs and is accompanied by an increased risk for the development of impaired cognitive function [27-31]. In this regard, functional magnetic resonance imaging studies in combination with cognitive tests in lean and obese individuals are under way to identify the related brain areas.

Although the mechanisms by which obesity causes insulin resistance in the brain are largely unknown, signalling mechanisms through surface receptors such as the TLRs are a proposed link. In particular, TLR2 and TLR4 receptors are expressed in brain tissues and are stimulated by increasing levels of saturated NEFA [32], and a loss-of-function mutation in TLR4 receptors protects mice from diet-induced obesity and insulin resistance in the periphery [23]; however, insulin signalling of the brain was not investigated in that experiment. From our study, it now 
becomes evident that in mice with defective TLR-receptor signalling, insulin action in the brain is enhanced and correlates with improved activity in the slow frequency bands and locomotor activity, suggesting that NEFAs and/ or cytokines from the metabolically active lipid store in the periphery mediate impaired insulin action in the brain that finally leads to physical inactivity in obesity. Compatible with our hypothesis, studies in humans demonstrated that insulin-mediated cortical activity in the theta frequency band is diminished in the presence of elevated levels of saturated NEFAs [33].

To define the related mechanisms, we demonstrated that insulin promotes locomotor activity by activation of the PI3kinase pathway and, finally, closure of voltage-gated Kv1.3 potassium channels. Convincing evidence for this mechanism came from pharmacological inhibition of Kv1.3 channels that promoted locomotor activity in lean and even obese mice, and the fact that Kv1.3 knockout mice exhibited significantly increased total activity and lower body weight, while their total energy intake was comparable [34].

In summary, our data suggest that insulin is a key mediator that couples the metabolic state to electrical activity, and finally locomotion, and therefore closes the gap between insulin-mediated changes in cortical activity and its behavioural consequences. In our understanding, postprandial insulin levels signal the metabolic state to the brain and increase locomotor activity, whereas this circuit is disrupted in the presence of obesity. Thereby, adequate insulin action in the brain is the basis for the maintenance of locomotor activity by activation of brain activity in the slow frequency bands, while in obese mice, this effect is blunted and further aggravates physical inactivity.

Acknowledgements This work was supported by the Deutsche Forschungsgemeinschaft (grants KFO 114/2 to H.-U. Häring and HE 3653/3-1 to A. M. Hennige) and the Deutsche Diabetes Gesellschaft. We thank D. Neuscheler and E. Metzinger for excellent technical assistance and R. Lammers for providing the antibodies.

Duality of interest The authors declare that there is no duality of interest associated with this manuscript.

\section{References}

1. Tschritter O, Preissl H, Hennige AM et al (2006) The cerebrocortical response to hyperinsulinemia is reduced in overweight humans: a magnetoencephalographic study. Proc Natl Acad Sci USA 103:12103-12108

2. Kitamura T, Kahn CR, Accili D (2003) Insulin receptor knockout mice. Annu Rev Physiol 65:313-332

3. Hribal ML, Oriente F, Accili D (2002) Mouse models of insulin resistance. Am J Physiol Endocrinol Metab 282:E977-E981

4. Hallschmid M, Benedict C, Born J, Kern W (2007) Targeting metabolic and cognitive pathways of the CNS by intranasal insulin administration. Exp Opin Drug Deliv 4:319-322
5. Hallschmid M, Benedict C, Schultes B, Fehm HL, Born J, Kern W (2004) Intranasal insulin reduces body fat in men but not in women. Diabetes 53:3024-3029

6. Schubert M, Brazil DP, Burks DJ et al (2003) Insulin receptor substrate-2 deficiency impairs brain growth and promotes tau phosphorylation. J Neurosci 23:7084-7092

7. Bruning JC, Gautam D, Burks DJ et al (2000) Role of brain insulin receptor in control of body weight and reproduction. Science 289:2122-2125

8. Taguchi A, Wartschow LM, White MF (2007) Brain IRS2 signaling coordinates life span and nutrient homeostasis. Science 317:369-372

9. Obici S, Feng Z, Karkanias G, Baskin DG, Rossetti L (2002) Decreasing hypothalamic insulin receptors causes hyperphagia and insulin resistance in rats. Nat Neurosci 5:566-572

10. Havrankova J, Roth J, Brownstein M (1978) Insulin receptors are widely distributed in the central nervous system of the rat. Nature 272:827-829

11. White MF (2003) Insulin signaling in health and disease. Science 302:1710-1711

12. Tschritter O, Hennige AM, Preissl H et al (2009) Insulin effects on beta and theta activity in the human brain are differentially affected by ageing. Diabetologia 52:169-171

13. Tschritter O, Preissl H, Yokoyama Y, Machicao F, Haring HU, Fritsche A (2007) Variation in the FTO gene locus is associated with cerebrocortical insulin resistance in humans. Diabetologia 50:2602-2603

14. van Lier H, Drinkenburg WH, van Eeten YJ, Coenen AM (2004) Effects of diazepam and zolpidem on EEG beta frequencies are behavior-specific in rats. Neuropharmacology 47:163-174

15. Hennige AM, Sartorius T, Tschritter O et al (2006) Tissue selectivity of insulin detemir action in vivo. Diabetologia 49:1274-1282

16. Hennige AM, Stefan N, Kapp K et al (2006) Leptin downregulates insulin action through phosphorylation of serine-318 in insulin receptor substrate 1. FASEB J 20:1206-1208

17. Ronnefarth VM, Erbacher AI, Lamkemeyer T et al (2006) TLR2/ TLR4-independent neutrophil activation and recruitment upon endocytosis of nucleosomes reveals a new pathway of innate immunity in systemic lupus erythematosus. J Immunol 177:7740-7749

18. Hennige AM, Lehmann R, Weigert $C$ et al (2005) Insulin glulisine: insulin receptor signaling characteristics in vivo. Diabetes 54:361-366

19. Kellerer M, Koch M, Metzinger E, Mushack J, Capp E, Haring HU (1997) Leptin activates PI-3 kinase in C2C12 myotubes via janus kinase-2 (JAK- 2) and insulin receptor substrate-2 (IRS-2) dependent pathways. Diabetologia 40:1358-1362

20. Li JY, Kuo TB, Hsieh SS, Yang CC (2008) Changes in electroencephalogram and heart rate during treadmill exercise in the rat. Neurosci Lett 434:175-178

21. Hennige AM, Burks DJ, Ozcan U et al (2003) Upregulation of insulin receptor substrate-2 in pancreatic beta cells prevents diabetes. J Clin Invest 112:1521-1532

22. Fadool DA, Levitan IB (1998) Modulation of olfactory bulb neuron potassium current by tyrosine phosphorylation. J Neurosci 18:6126-6137

23. Tsukumo DM, Carvalho-Filho MA, Carvalheira JB et al (2007) Loss-of-function mutation in Toll-like receptor 4 prevents dietinduced obesity and insulin resistance. Diabetes 56:1986-1998

24. Tschritter O, Hennige AM, Preissl H et al (2007) Cerebrocortical Beta activity in overweight humans responds to insulin detemir. PLoS ONE 2:e1196

25. Slawinska U, Kasicki S (1998) The frequency of rat's hippocampal theta rhythm is related to the speed of locomotion. Brain Res 796:327-331

26. Ekstrom AD, Caplan JB, Ho E, Shattuck K, Fried I, Kahana MJ (2005) Human hippocampal theta activity during virtual navigation. Hippocampus 15:881-889 
27. Arvanitakis Z, Wilson RS, Bienias JL, Evans DA, Bennett DA (2004) Diabetes mellitus and risk of Alzheimer disease and decline in cognitive function. Arch Neurol 61:661-666

28. Yaffe K, Blackwell T, Kanaya AM, Davidowitz N, Barrett-Connor E, Krueger K (2004) Diabetes, impaired fasting glucose, and development of cognitive impairment in older women. Neurology 63:658-663

29. Luchsinger JA, Gustafson DR (2009) Adiposity and Alzheimer's disease. Curr Opin Clin Nutr Metab Care 12:15-21

30. Bruehl H, Wolf OT, Sweat V, Tirsi A, Richardson S, Convit A (2009) Modifiers of cognitive function and brain structure in middle-aged and elderly individuals with type 2 diabetes mellitus. Brain Res 1280:186-194
31. Munte TF, Heldmann M, Hinrichs H et al (2008) Contribution of subcortical structures to cognition assessed with invasive electrophysiology in humans. Front Neurosci 2:72-78

32. Lee JY, Hwang DH (2006) The modulation of inflammatory gene expression by lipids: mediation through Toll-like receptors. Mol Cells 21:174-185

33. Tschritter O, Preissl H, Hennige AM et al (2009) The insulin effect on cerebrocortical theta activity is associated with serum concentrations of saturated non-esterified fatty acids. J Clin Endocrinol Metab (in press)

34. Fadool DA, Tucker K, Perkins R et al (2004) Kv1.3 channel genetargeted deletion produces "Super-Smeller Mice" with altered glomeruli, interacting scaffolding proteins, and biophysics. Neuron 41:389-404 